\title{
COMET strongly supported the development and implementation of medium-term topical research roadmaps consistent with the ALLIANCE Strategic Research Agenda
}

To cite this article before publication: Jacqueline Garnier-Laplace et al 2017 J. Radiol. Prot. in press https://doi.org/10.1088/1361-6498/aa9c0a

\section{Manuscript version: Accepted Manuscript}

Accepted Manuscript is "the version of the article accepted for publication including all changes made as a result of the peer review process, and which may also include the addition to the article by IOP Publishing of a header, an article ID, a cover sheet and/or an 'Accepted

Manuscript' watermark, but excluding any other editing, typesetting or other changes made by IOP Publishing and/or its licensors"

This Accepted Manuscript is (C) 2017 IOP Publishing Ltd.

During the embargo period (the 12 month period from the publication of the Version of Record of this article), the Accepted Manuscript is fully protected by copyright and cannot be reused or reposted elsewhere.

As the Version of Record of this article is going to be / has been published on a subscription basis, this Accepted Manuscript is available for reuse under a CC BY-NC-ND 3.0 licence after the 12 month embargo period.

After the embargo period, everyone is permitted to use copy and redistribute this article for non-commercial purposes only, provided that they adhere to all the terms of the licence https://creativecommons.org/licences/by-nc-nd/3.0

Although reasonable endeavours have been taken to obtain all necessary permissions from third parties to include their copyrighted content within this article, their full citation and copyright line may not be present in this Accepted Manuscript version. Before using any content from this article, please refer to the Version of Record on IOPscience once published for full citation and copyright details, as permissions will likely be required. All third party content is fully copyright protected, unless specifically stated otherwise in the figure caption in the Version of Record. 


\title{
COMET strongly supported the development and implementation of medium-term topical research roadmaps consistent with the ALLIANCE Strategic Research Agenda
}

\author{
J. Garnier-Laplace ${ }^{1}$, H. Vandenhove ${ }^{2}$, N. Beresford ${ }^{3}$, M. Muikku $^{4}$, A. Real $^{5}$
}

${ }^{1}$ Institut de Radioprotection et de Sûreté Nucléaire (IRSN), Pôle Santé et Environnement, CadaracheBatiment 159, BP 3, 13115 Saint-Paul-lez-Durance, France

${ }^{2}$ Belgian Nuclear Research Centre (SCK•CEN), Boeretang 200, 2400 Mol, Belgium

${ }^{3}$ Natural Environment Research Council, Centre for Ecology \& Hydrology (NERC-CEH), Lancaster Environment Centre, Library Av., Bailrigg, Lancaster, LA1 4AP, United Kingdom

${ }^{4}$ Radiation and Nuclear Safety Authority (STUK), P.O. Box 14, 00811 Helsinki, Finland

${ }^{5}$ Spanish Research Centre in Energy, Environment and Technology (CIEMAT), Avenida Complutense 40, Madrid 28040, Spain

E-mail: jacqueline.garnier-laplace@irsn.fr

Short title: Topical roadmaps and a strategic research agenda for radioecology

\begin{abstract}
The ALLIANCE ${ }^{1}$ Strategic Research Agenda (SRA) initiated by the STAR ${ }^{2}$ Network of Excellence and integrated in the research strategy implemented by the COMET consortium, defines a long-term vision of the needs for, and implementation of, research in radioecology. This reference document, reflecting views from many stakeholders groups and researchers, serves as an input to those responsible for defining EU research call topics through the ALLIANCE SRA statement delivered each year to the EJP CONCERT $^{3}$ (2015-2020). This statement highlights a focused number of priorities for funding. Research in radioecology and related sciences is justified by various drivers, such as policy changes, scientific advances and knowledge gaps, radiological risk perception by the public, and a growing awareness of interconnections between human and ecosystem health. The SRA is being complemented by topical roadmaps that have

${ }^{3}$ EJP-CONCERT: European Joint Programme for the Integration of Radiation Protection Research, http://www.concert-
\end{abstract}

${ }^{1}$ http://www.er-alliance.eu/

${ }^{2}$ www.star-radioecology.org $\underline{\text { h2020.eu }}$ 
been initiated by the COMET ${ }^{4}$ EC-funded project, with the help and endorsement of the ALLIANCE. The strategy underlying roadmap development is driven by the need for improved mechanistic understanding across radioecology. By meeting this need, we can provide fit-for-purpose human and environmental impact/risk assessments in support of protection of man and the environment in interaction with society and for the three exposure situations defined by the ICRP (i.e., planned, existing and emergency). Within the framework of the EJP CONCERT the development of a joint roadmap is under discussion among all the European research platforms and will highlight the major research needs for the whole radiation protection field and how these are likely to be addressed by 2030 .

\section{Introduction: COMET served the ALLIANCE SRA and its drivers}

The COMET project (COordination and iMplementation of a pan-European instrumenT for radioecology, a combined Collaborative Project and Coordination and Support Action under the EC/Euratom 7th Framework Programme) played a central role in interacting with the European radioecology ALLIANCE. COMET has updated research priority needs in radioecology and made more concrete activities in a number of fields through the implementation of various topical roadmaps (Muikku et al., this issue). The ALLIANCE Strategic Research Agenda (SRA) is a living document, initiated by the STAR Network of Excellence, defining a long-term vision (20 years) on the needs for, and implementation of, research in radioecology (STAR consortium, 2014). This SRA has been elaborated at the European level, in connexion with the main international organisations acting in the field of radiation protection (e.g., World Health Organization, United Nations Scientific Committee on the Effects of Atomic Radiation, International Commission on Radiological Protection, International Atomic Energy Agency) and with similar scientific networks worldwide (e.g., National Center for Radioecology (NCoRE) within the United States, International Union of Radioecology). The SRA constitutes a reference document that takes account of stakeholders' inputs. The current version released in September 2013, integrates more than one hundred comments collected during an international workshop (Paris, November 2012) and a wide on-line consultation undertaken during the summer of 2012 from a variety of stakeholders. Consulted stakeholders include NGOs, nuclear industry representatives, regulators, funding agencies and scientific non-profit societies from other environmental disciplines. Since the COMET project, this SRA serves as an input to those responsible for defining EU research calls.

A number of different drivers, that are still applicable, steered the development of the SRA:

${ }^{4}$ COMET- FP7 Euratom Fission-2013- project number: 604974, Start June 1, 2013, duration 48 months- www.cometradioecology.org 
- Credibility concerns: Uncertainties and lack of predictive power in risk assessments are major contributors to the public's lack of confidence in the radiological sciences, and are thus a major driver for additional research.

- Generating trust: The general public needs to have the necessary confidence in decision makers to be able to trust their judgements, advice and recommendations. The increasing environmental awareness of the public reinforces the need for clarity and transparency within the scientific community relative to the long-term ecological consequences of any nuclear accident or chronic exposure situation. For example, the divergent scientific opinions on the effects on human health and wildlife in the Chernobyl exclusion zone do little for public confidence. This means that multidisciplinary opinions, either consensual or divergent, have to be shared and used to revisit evidence and related actions. Even more, as it has been demonstrated in the event of a nuclear accident, scientific consensus does not always translate into consensus of action by authorities (e.g., Oughton, 2012; Hasegawa, 2012; Beresford et al., 2016).

- New paradigms and scientific advances: Recent changes in understanding relevant to radiation effects on humans are also relevant in radioecology. New ideas are being incorporated into the science, such as epigenetic changes, bystander effects, genomic instability and population consequences from multigenerational exposures. Radioecology also must capitalise on the rapid advances in the "-omic" sciences to help develop mechanistic explanations and early warning biomarkers.

- Changing policy: The present framework of radiological protection is moving towards the need to demonstrate the protection of the environment explicitly as opposed to an assumption of protection. For example, this is seen in the revised versions of the international Basic Safety Standards (BSS) (IAEA, 2011) and to a lesser extent, in the Euratom BSS (EURATOM COUNCIL, 2013) in their interim or draft status at the time of the SRA inception.

- Integration issues: Recognition that radioecology's future success, such as for example, meeting stakeholder needs, will require integration into the whole system of radiological protection. The recent ICRP rearrangement of its Committees to address protection of people and the enyironment in an integrated manner is a further indication of the recognition of this need.

- Potential risks: The lessons learned following the Chernobyl and Fukushima- nuclear accidents demonstrate a number of knowledge gaps, with excessively large uncertainties associated with a number of environmental processes governing the fate and effect of radionuclides within ecosystems. This situation results in uncertainties in human and wildlife dose assessments, making it difficult to robustly support the decision-making process. 
- Impact of controversial findings: In the context of ecological consequences of nuclear accidents, the growing number of peer-reviewed publications alleging ecosystem damage from radiation doses at the level of natural background (and sometimes even below) undermine credibility in radioecology. If such findings evidencing biological effects of ionising radiation at very low dose rates are correct, both the systems for environmental protection and protection of humans from ionising radiation will be questioned.

Since the last version of the SRA was produced, other drivers have emerged and enhanced the relevancy of having a SRA-type document as a reference to express and prioritise research activities.

- The growing awareness by the public of the importance of the global quality of environmental resources and biodiversity, with many examples of national regulations directed to protection of the environment as a whole (e.g., nature conservation, uses of environmental resources, air, soil, water quality). Even more significantly, human and ecosystem health are now recognised as strongly interconnected as evidenced for example, by several principles and goals for sustainable development recently agreed in the 2030 development agenda of the United Nations (UN, 2015).

- The need for an integrated approach in order to improve the degree of realism in dose assessments (and therefore in evaluations of the associated impacts or risks) either for the public or wildlife for a wide range of exposure situations. Going towards more site-specific, individual (for humans) dose assessments to enhance realism imply a need to improve risk communication among stakeholders as to the most significant uncertainties.

- The need to develop applied research activities in order to solve several statements of the new Euratom BSS that are related to radioecology. These needs are urgent since the BSS has to be translated into corresponding national laws before February 2018.

Finally, the SRA highlights the required scientific knowledge and methodological/technical know-how for the main components of any environmental risk assessment. It identifies three scientific challenges and fifteen associated research lines, consistent with a strategic vision of what radioecology can achieve in the future via a prioritisation of efforts. These challenges are:

- Challenge 1 - To Predict Human and Wildlife Exposure in a Robust Way by Quantifying Key Processes that Influence Radionuclide Transfers and Exposure;

- Challenge 2 - To Determine Ecological Consequences under Realistic Exposure Conditions;

- Challenge 3 - To Improve Human and Environmental Protection by Integrating Radioecology (Fig.1).

The SRA has been integrated in the research strategy implemented by the COMET consortium, and one of the main outputs is the SRA-associated topical roadmaps that were launched during COMET. These topical roadmaps are presented in detail in COMET D2.4 annex (Garnier-Laplace et al., 2017)] 
and will stay active and continue to develop after the end of COMET under the auspices of the ALLIANCE (Muikku et al., this issue). For information, external experts will be asked to identify any additional or new drivers. A new version of the SRA will be released accordingly in November 2019 as planned under the EJP-CONCERT.

\section{Building the SRA-associated roadmaps}

The SRA is being complemented by topical roadmaps that have been initiated by the COMET ECfunded project, with the help and endorsement of the ALLIANCE. The strategy underlying roadmap development is driven by the need to provide fit-for-purpose human and environmental impact/risk assessments in support of protection of man and the environment in interaction with society (connecting sciences included social sciences and humanities, risk management including communication, economy), whatever the environmental exposure situation. Some of the research areas for radioecology are also relevant for post-emergency management and low-dose effect research and provide a catalyst to further develop collaboration between the various radiation protection specialties and programmes.

For the purpose of elaborating topical roadmaps, the overall strategy described for the 3 challenges of the SRA was translated to an approach and expected outcome as follows:

- For Challenge 1:

o Approach: Improve human and environmental dose and impact assessments by mechanistic/process-based modelling of environmental transfer and exposure in the biosphere.

o Expected outcome: Fit-for-purpose environmental models to support human and wildlife impact assessment and risk management.

- For Challenge 2:

o Approach: Unravel causes and mechanisms of radiation-induced effects in wildlife from molecular to individual and population scales.

o Expected outcome: Knowledge of the causes of biological effects to detect early damage and to protect wildlife populations.

- For Challenge 3:

o Approach: Improve risk characterisation by better quantification of uncertainty and variability of exposure and effects.

o Expected outcome: An integrated approach to enhanced risk characterisation and communication (connecting science, economy \& society).

After a transitional roadmap was released by COMET in 2013 as an initial basis for an implementation plan (Vandenhove et al., 2013), several topical roadmap working groups (WG) each of them dealing with specific scientific areas were initiated. Each WG aimed to build a 5-year roadmap. Five topical areas wêre selected as listed below, each topic being briefly justified [italic characters in brackets]: 
1. Atmospheric transfer processes [The Fukushima accident highlighted some lacks in processes considered in atmospheric dispersion and inhalation dose assessments, the deposition of atmospheric releases and long-term secondary emissions from previous deposits e.g. from snow and fog];

2. marine radioecology [The Fukushima accident showed a lack of robust marine radioecological models];

3. human food-chain modelling [Actual decision-support-systems are to be adapted to other regions of Europe and radioecological models to be improved];

4. environmental issues associated with naturally-occurring radioactive materials (NORM) [NORM sites often close to settlements, which require appropriate management and/or remediation];

5. inter- and intra-species radiation sensitivity and transgenerational effects [The major concern of long-term biological effects of low radiation doses acts as a driver to improve our knowledge on long-term/transgenerational effects and differences in radiation sensitivity].

The WG focus extended from basic science (mechanistic understanding) to applications that would improve radiation protection, communication with society, and assist decision-making processes. Research proposed by the WGs is intended to interlink the 3 different challenges presented in the SRA. Prioritising radioecology research topics within roadmaps to areas relevant for post-emergency management and low-dose effect research has promoted collaboration between the four existing European radiation protection platforms ${ }^{5}$. Several criteria were considered to prioritise the research in the roadmaps: impact, achievability, relevance and public perception, and good science. Table 1 gives a brief description of those criteria.

On the basis of the COMET WG initiated topical roadmaps, ALLIANCE now has the materials to build a global roadmap in the lead up to Horizon 2030, which is to be released under EJP-CONCERT in November 2017, in a similar manner to other relevant research platforms. This global roadmap, based on building blocks constituted by the COMET WG topical roadmaps, will be developed based on three elements:

- Each topical roadmap will describe its own life cycle by scheduling research activities across the 2015-2030 timeline and assessing the Technology Readiness Level of each major research activity (adapted from TRL scales - from "basic research" to "ready to use"). This will give visibility as to which research activities require further work as well as how to make use of infrastructures/observatory sites.

5 EURADOS: www.eurados.org/ for dosimetry ; EURAMED: http://www.eibir.org/scientific-activities/jointinitiatives/european-alliance-for-medical-radiation-protection-research-euramed// for medical applications; MELODI: http://www.melodi-online.eu/ for low dose risks; NERIS: http://www.eu-neris.net/ for emergency preparedness and postaccidental situations 
- The SRA WG will examine in depth whether other drivers and topics are needed to complement the building blocks of the global roadmap, where external funds, in addition to national funding, will be required.

- The ALLIANCE global roadmap will be established and viewed as a global picture of the main achievements planned for the next 15 years.

\section{Sustainability after COMET}

Sustainability after COMET is ensured by the commitment of ALLIANCE activities within the SRA/roadmap and the various topical roadmap WGs. The milestones are defined through the ALLIANCE involvement in the EJP-CONCERT (2015-2020), where ALLIANCE is a partner along with the other research platforms (MELODI, EURADOS, NERIS, and more recently EURAMED for medical applications). WP2 (Integration and SRA development in radiation protection research) and WP3 (Priority research and joint programming needs in the perspective of European integration) of EJP-CONCERT provide a forum for the discussion of the drivers of the SRA update in a harmonised manner with the other platforms. Additionally, a new mechanism has been adopted to help to define research priorities, as is required for the two calls for proposals managed by CONCERT WP4 (Management of the Open RTD Calls). The mechanism consists of annual requests of each platform to rank and justify a number of priorities extracted from their respective SRAs. The ALLIANCE has produced three annual SRA statements $(2015,2016$ and 2017) for EJP-CONCERT to provide and justify research priorities for radioecology in the short- and medium-term. The selection of priorities was based on the combination of the conclusions of the OPERRA e-Survey (Perko et al., 2015), the research progress in recent and on-going EC-funded projects and consolidation by the ALLIANCE SRA/roadmap WG and all ALLIANCE members considering selection criteria (impact, relevance, good science and feasibility). Among the priorities identified in the SRA statements, two focus on reducing uncertainty in exposure and dose assessments for human and wildlife radiation protection:

- Environmental availability and impact of radionuclides in terrestrial, freshwater and marine ecosystems (including the human food chain) and interactions with the atmosphere, incorporating physical, chemical and/or biological processes. Expected advances are outputs such as: Validated process-based model parameterisation, characterisation of variability and uncertainty, and guidance for fit-for-purpose models.

- Development of models/tools, and datasets for their calibration and validation, and guidance to select and evaluate the effectiveness of different remediation strategies in long-lasting exposure situations (e.g. nuclear accidents, issues related to NORM or TeNORM contaminated sites).

While two priorities focus on reducing uncertainty in effect assessment for wildlife radiation protection: 
- Biomarkers of exposure and effects on living organisms as operational outcomes of a mechanistic understanding of intra- and inter-species variation of radiosensitivity to chronic low-dose exposure situations.

- Multiple stressors and modulation of radiation effects in living organisms.

Reducing uncertainties will be achieved by: (i) improving the understanding of elementary processes and their modelling and (ii) improving the predictability of the models used. Integrated risk assessment combines many uncertainties associated with: the characterisation of source-terms, the fate of radionuclides (and other pollutants) in the environment, radiological and non-radiological exposures and their impacts on human and environmental health. Risk estimates are generally obtained by using validated models and/or field data. The two sources of information (modelled and empirical data) both contribute to uncertainties that need to be assessed, i.e. they have to be taken into account to inform and support decision making.

Following COMET, under EJP-CONCERT the ALLIANCE will contribute to the Joint Roadmap based on the roadmaps produced by each of the platforms (i.e. ALLIANCE, MELODI, NERIS, EURADOS, EURAMED). The ALLIANCE contribution to this Joint Roadmap reinforces the crosscutting features of radioecology (e.g., accurate characterisation of human exposure needs knowledge and know-how on radionuclide fate in the various environmental compartments). The joint brainstorming with all the platforms has just begun and will be structured by the major societal issues expressed by stakeholders groups. Examples of such issues include the nuclear legacy impact on public health and the environment, how the threat of a radiological terrorist act should be addressed, how to share radioprotection culture among stakeholders and how to deal with the consequences of a nuclear accident or incident.

The era of integration of research for radiation protection in Europe has started. For radioecologyrelated issues, STAR and COMET, both supported by the ALLIANCE, have made a significant contribution by proposing, evaluating and consolidating the major integration mechanisms as described in the statement paper by Muikku et al. (this issue).

\section{Conclusion and major lessons learned}

Regarding the research prioritisation and integration mechanisms along with instruments such as the SRA and roadmaps that have been developed under COMET, the COMET Steering Committee acknowledged that "one strength of COMET was the use of Working Groups (WGs) to develop roadmaps. More generally, having a WG that both defines a research agenda and has a remit to put activities in place to fulfil that agenda is important in helping to ensure that the work actually gets done". The various roadmaps are regularly reviewed by the ALLIANCE board at a higher level to ensure that they are being consistent and complementary, without substantial overlaps or significant gaps. Further effort by the ALLIANCE is still required to ensure that "the roadmaps are translated 
1

effectively into adequately funded research programmes, with funding at intra-national, national and international levels".

Thanks to COMET, the ALLIANCE has now the necessary constituents to develop a global roadmap in the lead up to Horizon 2030. This global roadmap will provide visibility to research priorities consistent with stakeholders' needs and request for additional funding.

Roadmapping is of major importance in terms of European research governance. Regarding the roadmaps dedicated to radioecology, the ALLIANCE will coordinate a stakeholders' consultation phase at the relevant juncture and ensure that such outcomes are disseminated widely and transparently.

\section{Acknowledgments}

This work has been partially supported by the European Commission under the 7th Framework Programme through the COMET - COordination and iMplementation of a pan-European instrumenT for radioecology, grant agreement no: 604974. The authors would like to thank the other members of the ALLIANCE SRA/roadmap Working Group for the fruitful discussion all along our advances, $C$. Adam-Guillermin, T. Arnold, C. Duffa, N. Horemans, O. Masson, S. Sachs, J. Tschiersch, C. Berthomieu, L. Currivan, P. Krajewski, F. Legarda, B. Michalik, M. J. Madruga, M. Merroun, J. Popic, P. Nogueira, B. Salbu, M. Steiner, M. Vidal, J. Vives I Batlle. Authors are also grateful to Mike Thorne for his high availability and very helpful and relevant advice. We are also thankful to the anonymous referees whose recommendations helped to make this position paper clearer.

\section{References}

Beresford, N.A., Fesenko, S., Konoplev, A., Skuterud, L., Smith, J.T., Voigt, G., 2016. Thirty years after the Chernobyl accident: What lessons have we learnt? Journal of Environmental Radioactivity, 157, pp. 77-89. DOI: 10.1016/j.jenvrad.2016.02.003

European Commission, 2013. COUNCIL DIRECTIVE 2013/59/Euratom of 5 December 2013 laying down basic safety standards for protection against the dangers arising from exposure to ionising radiation, and repealing Directives 89/618/Euratom, 90/641/Euratom, 96/29/Euratom, 97/43/Euratom and 2003/122/Euratom.

Garnier-Laplace, J,, Vandenhove, H., Real, A., 2017. Deliverable 2.4 - Update of the Strategic Research Agenda for Radioecology. EC-COMET project - Fission-2012-3.4.1-604794. 
Hasegawa, K., 2012. Facing Nuclear Risks: Lessons from the Fukushima Nuclear Disaster. International Journal of Japanese Sociology, 21 (1), pp. 84-91. DOI: 10.1111/j.14756781.2012.01164.x

IAEA, 2011. Radiation Protection and safety of radiation sources: International basic safety standards Sources. Interim Edition. General Safety Requirements Part 3 - nGSR Part 3 (Interim). 96 pp. and appendixs, International Atomic Energy Agency, Vienna, Austria.

Muikku, M., Sirkka, L., Beresford, N.A., Garnier-Laplace, J., Real, A., Thorne, M., vandenhove, H., Willrodt, C., 2017. Sustainability and integration of radioecology - position paper. This issue.

Oughton, D.H., 2011. Social and ethical issues in environmental risk management. Integrated Environmental Assessment and Management, 7 (3), pp. 404-405. DOI: 10.1002/ieam.226

Perko, T., Turcanu, C., Sirkka, L., 2015. Analyses of stakeholder questionnaire/responses. OPERRA Deliverable D4.5, Contract (grant agreement) number: 604984, 130 p.

STAR consortium, 2014. Strategic Research Agenda for Radioecology - An updated version with stakeholder input. Issued on 24/02/2014, 92 p. DELIVERABLE (D-N².5) Contract Number: Fission2010-3.5.1-269672. https://wiki.ceh.ac.uk/x/YoFsD.

United Nations, 2015. Transforming our world : the 2030 Agenda for Sustainable Development. $\mathrm{A} / \mathrm{RES} / 70 / 1,41 \mathrm{p}$.

Vandenhove, H., J. Garnier-Laplace, A. Real, N. Horemans, J. Vives i Batlle, N.A. Beresford, A. Liland, L. Février, C. Adam-Guillermin, K. Beaugelin-Seiller, C.L. Barnett, C. Bradshaw, R. Gilbin, T.G. Hinton, B.J. Howard, T.K. Ikäheimonen, M. Muikku, B. Salbu, M. SimonCornu, K. Stark, M. Steiner, 2013. Deliverable 2.1 -Towards a First Phase Radioecology Alliance RTD Roadmap and Implementation Plan, EC-COMET project - Fission-2012-3.4.1-604794 (restricted). 


\section{List of figure captions}

Figure 1: Simplified presentation of the content of the ALLIANCE Strategic Research Agenda

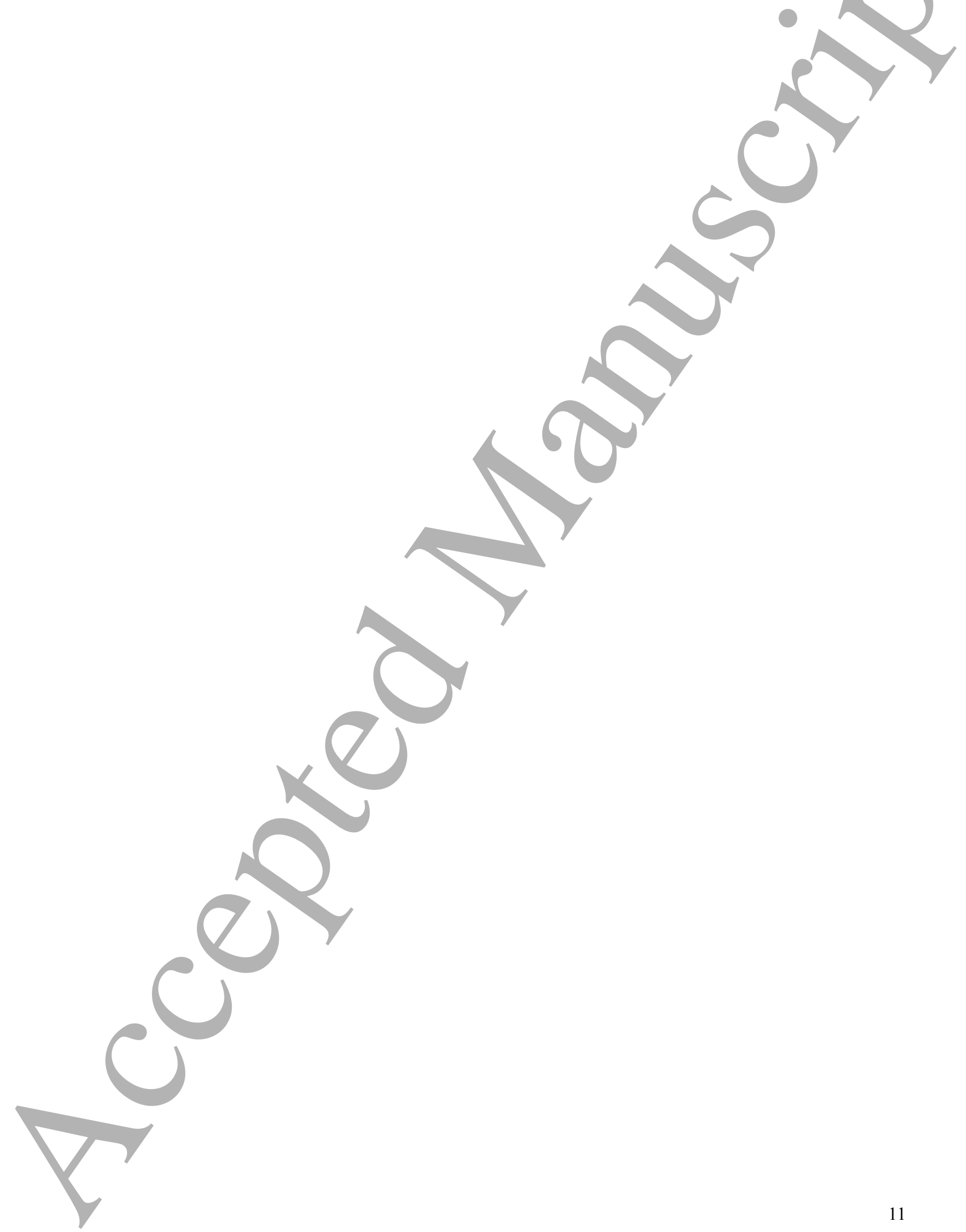




\section{The Strategic Research Agenda on Radioecology}

The Strategic Research Agenda (SRA) developed by STAR and ALLIANCE:

- Defines a long term vision on the needs and implementation of research in Radioecology.

- Aims to be useful for science and society, shared by stakeholders and researchers and realistic from an operational and scientific point of view.

- Is a document open for debate with all relevant actors: research bodies, authorities and other related radiation protection Associations, and other stakeholders.

- Highlights 3 scientific challenges with 15 associated research lines

- Responds to the question:

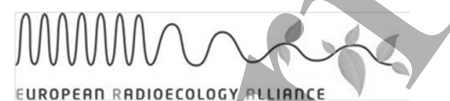

What topics, if critically addressed over the next 20 years, would significantly advance radioecology?

Challenge 1: Predict human and wildlife exposure in a robust way by quantifying key processes that influence radionuclide transfers and exposure. Addressing four research lines:

1. Identify and mathematically represent key processes that significantly contribute to the environmental transfers of radionuclides and resultant exposures of humans and wildlife.

2. Acquire the data necessary for parameterisation of the key processes controlling the transfer of radionuclides.

3. Develop transfer and exposure models that incorporate physical, chemical and biological interactions, and enable predictions to be made spatially and temporally.

4. Represent radionuclide transfer and exposure at a landscape or global environmental level with an indication of the associated uncertainty.

Challenge 2: Determine ecological consequences under realistic exposure conditions. Addressing five research lines:

1. Establish processes link radiation induced effects in wildlife from molecular to individual levels of biological complexity.

2. Determine what causes intra-species and interspecies differences in radiosensitivity (i.e. among cell types, tissues, life stages, among contrasted life histories, influence' of ecological characteristics including habitats, behaviour, feeding regime...).

3. Understand the interactions between ionising radiation effects and other co-stressors.

4. Identify the mechanisms underlying multigenerational responses to long-term ecologically relevant exposures: maternal effects, hereditary effects, adaptive responses, genomic instability, and epigenetic changes/transformations/processes.

5. Understand how radiation effects combine in a broader ecological context at higher levels of biological organisation (population dynamics, trophic interactions, indirect effects at the community level, and consequences for ecosystem functioning).

Challenge 3: Improve human and environmental protection by integrating radioecology. Addressing six research lines:

1. Integrate uncertainty and variability from transfer modelling, exposure assessment, and effects characterisation into risk characterisation.

2. Integrate human and environmental protection frameworks.

3. Integrate the risk assessment frameworks for ionising radiation and chemicals.

4. Provide a multi-criteria perspective in support of optimised decision making.

5. Integrate ecosystem approaches, such as ecosystem services and ecological economics, within radioecology.

6. Integrate decision support systems.

"The SRA is clearly the product of substantial international discussion and evaluation of different perspectives on the medium-term future of radigecologk. The iesult is a logical collection of research themes that, if addressed fully, would not only revolutionise radioecology but also ecotoxicology and ultimately integrated environmental management" Comment received from a participant in the SRA questionnaire done in 2012

Figure 1 - Simplified presentation of the content of the ALLIANCE Strategic Research Agenda 
Table 1: Final List of Criteria for Research Prioritization

\begin{tabular}{|c|c|c|}
\hline $\begin{array}{l}\text { Broad } \\
\text { Area }\end{array}$ & Specific criterion & Comments \\
\hline \multirow{4}{*}{ 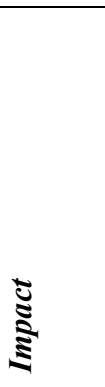 } & $\begin{array}{l}\text { Substantial enhancement of } \\
\text { knowledge }\end{array}$ & $\begin{array}{l}\text { Required to give confidence to stakeholders and provide an improved } \\
\text { capability giving greater confidence in decision making. }\end{array}$ \\
\hline & $\begin{array}{l}\text { Addresses major unresolved } \\
\text { issues relevant to radiological } \\
\text { protection }\end{array}$ & $\begin{array}{l}\text { Ensures that the overall enhancement of } \mathrm{k} \\
\text { specific requirements of the radiological prote }\end{array}$ \\
\hline & Practical ap & $\begin{array}{l}\text { Results can be used directly or readily adapted for use by legislators, } \\
\text { regulators, operators and other interested parties }\end{array}$ \\
\hline & Public relevance & Seen to be addressing issues of public interest or concern. \\
\hline \multirow[b]{4}{*}{ 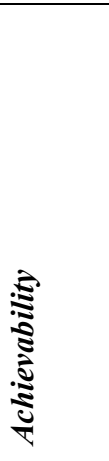 } & $\begin{array}{l}\text { Realistic on a five-year } \\
\text { timescale }\end{array}$ & $\begin{array}{l}\text { Or at least feasible to undertake in stages, so that well-defined interim } \\
\text { goals can be achieved and demonstrated within five years. }\end{array}$ \\
\hline & Suffic & $\begin{array}{l}\text { Sufficient internal resources within the ALLIANCE to deliver a useful } \\
\text { product even in the absence of external funding. }\end{array}$ \\
\hline & $\begin{array}{l}\text { Adequate basis in current } \\
\text { knowledge and experience }\end{array}$ & $\begin{array}{l}\text { Builds on existing knowledge and makes use of experience and facilities } \\
\text { that are available within the research community. }\end{array}$ \\
\hline & $\begin{array}{l}\text { Appropriate level } \\
\text { failure }\end{array}$ & $\begin{array}{l}\text { Suitable balance between high risk and low risk components, i.e. there is a } \\
\text { need to ensure that some useful outcome is delivered, but this should not } \\
\text { stifle the need to undertake speculative work that could lead to a high } \\
\text { return if it is successful. }\end{array}$ \\
\hline \multirow{6}{*}{ 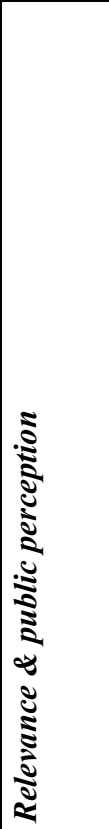 } & $\begin{array}{l}\text { High relevance } \\
\text { of humans }\end{array}$ & $\begin{array}{l}\text { Implies a focus on the radionuclides and pathways that contribute most to } \\
\text { doses to humans in a variety of assessment contexts. }\end{array}$ \\
\hline & $\begin{array}{l}\text { High relevance for } \\
\text { protection of wildlife }\end{array}$ & $\begin{array}{l}\text { Includes consideration of biodiversity, ecosystem performance and health, } \\
\text { sustainability and protection of endangered species. Again, implies a focus } \\
\text { on key radionuclides and pathways in a variety of assessment contexts. }\end{array}$ \\
\hline & $\begin{array}{l}\text { Rele } \\
\text { in } \text { ar }\end{array}$ & $\begin{array}{l}\text { These research initiatives include studies on the effects of low doses, } \\
\text { developments in emergency planning and preparedness and dosimetry. }\end{array}$ \\
\hline & $\operatorname{Impo}$ & $\begin{array}{l}\text { Are the results to be obtained of importance from a public perspective } \\
\text { (irrespective of their significance for radiological protection? Are results of } \\
\text { relevance to an issue of great public interest. Will results be of direct } \\
\text { relevance to members of the public in enhancing their understanding of a } \\
\text { given situation and informing their decision making. }\end{array}$ \\
\hline & Conv & $\begin{array}{l}\text { Has provision been made to demonstrate why a member of the public } \\
\text { should place credence in the results to be obtained, e.g. by explaining the } \\
\text { background to the work in appropriate language and showing how it fits } \\
\text { within a broader body of scientific knowledge? }\end{array}$ \\
\hline & $\log$ & $\begin{array}{l}\text { Builds on existing understanding and addresses a generally recognised } \\
\text { deficiency in that understanding (e.g. due to lack of data or an appropriate } \\
\text { conceptual model of the processes and mechanisms of relevance). }\end{array}$ \\
\hline \multirow{2}{*}{ 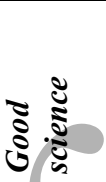 } & en & $\begin{array}{l}\text { The research should be targeted to support or refute one or more } \\
\text { hypotheses of importance for understanding the issue being considered. }\end{array}$ \\
\hline & Innovative & $\begin{array}{l}\text { In so far as innovation enhances our ability to answer the key questions } \\
\text { posed by the research topic. }\end{array}$ \\
\hline
\end{tabular}

